\title{
Studies on Hydrogen Exchange. XII.1) Reaction Mechanism for Hydrogen Exchange of C-8 Hydrogen of Purine Ribosides
}

\author{
Mitsuaki Maeda, Mineo Saneyoshi and Yutaka Kawazoe \\ National Cancer Center Research Institute $\left.{ }^{2}\right)$
}

(Received January 28, 1971)

\begin{abstract}
The reaction mechanism for the hydrogen exchange of C-8 hydrogens of purine ribosides was discussed on the basis of the $\mathrm{pD}$-rate profiles and the effect of 6 -substituents on the rate. It was shown that the rate depended on concentrations of the purine and $\mathrm{D}_{2} \mathrm{O}$ and that the observed second-order rate constant was expressed as $k_{\mathrm{OD}}-\mathrm{K}_{\mathrm{D}_{2} \mathrm{O}} / \mathrm{Ka}\left(\mathrm{N}_{7}\right)$ where $k_{O D}$ - was the rate constant for hydrogen exchange of $\mathrm{N}_{7}$-protonated purines by attack with the $\mathrm{OD}^{-}, \mathrm{K}_{\mathrm{D}_{2} \mathrm{O}}$ was the dissociation constant of $\mathrm{D}_{2} \mathrm{O}$, and $\mathrm{Ka}\left(\mathrm{N}_{7}\right)$ was the dissociation constant of $\mathrm{N}_{7}$-protonated purines.
\end{abstract}

Aromatic ring hydrogens can undergo inoic hydrogen exchange with active hydrogens of protic solvent molecules when they are activated by the ring heteroatoms in such a way that the carbanion structure formed by deprotonation from the $\mathrm{C}-\mathrm{H}$ function concerned is stabilized mainly through the ylide formation, inductive effect, and/or d- $\sigma$ interaction with the adjacent heteroatoms such as nitrogen, sulfur, etc. Purine derivatives including polynucleotides and natural nucleic acids undergo hydrogen exchange at their C-8 position under various conditions. ${ }^{3-7)}$ Many papers have dealt with this problem mainly from the biological interest but the reaction mechanism involved has not completely been elucidated yet. ${ }^{3-16)}$

This paper describes the mechanism involved in the exchange of C-8 hydrogens of purine ribosides, discussed on the basis of kinetic study of the reaction.

\section{Experimental}

Compounds_-Adenosine and inosine were kindly supplied by Kojin Co., Ltd. and Ajimonoto Co., Ltd., respectively. All the other derivatives used were synthesized in our laboratory according to the authentic preparative methods: 1-methylinosine, ${ }^{17}$ ) $\mathrm{N}_{6}$-methyladenosine, ${ }^{17}$ ) $\mathrm{N}_{6}, \mathrm{~N}_{6}$-dimethyladenosine, ${ }^{18)}$ 6-thioinosine, ${ }^{19}$ )

1) Part XI: Y. Kawazoe, M. Tsuda and T. Horie, Chem. Pharm. Bull. (Tokyo), 19, 429 (1971)

2) Location: Tsukiji, Chuo-ku, Tokyo.

3) M. Tomasz, Biochim. Biophys. Acta, 199, 18 (1970).

4) F. Doppler-Bernardi and G.Felsenfeld, Biopolymers, 8, 733 (1969).

5) K.R. Shelton and J.M. Clark, Jr., Biochem. Biophys. Res. Commun., 33, 850 (1968).

6) L.A. Ostermann, V.V. Adler, R. Bebelaschvily, L.P. Savothkina and Y.M. Varshavsky, Biokhimiya, 31,398 (1966).

7) C.C. McDonald, W.D. Phillips and J. Penswick, Biopolymers, 3, 609 (1965).

8) W.J. Wechter, Coll. Czech. Chem. Commun., 35, 2003 (1970).

9) F. Bergmann, D. Lichtenberg and Z. Neimann, J. Chem. Soc. (D), Chem. Commun., 1969, 992.

10) P.O.P.Ts'o, N.S. Kondo, R.K. Robins and A.D. Broom, J. Am. Chem. Soc., 91, 5625 (1969).

11) K.R. Shelton and J.M. Clark, Jr., Biochemistry, 6, 2753 (1967).

12) J.M. Rice and G.O. Dudek, J. Am. Chem. Soc., 89, 2719 (1967).

13) J.M. Harris and J.C. Randall, Chem. Ind., 1965, 1728.

14) F.J. Bullock and O. Jardetzky, J. Org. Chem., 29, 1988 (1964).

15) M.P. Schweizer, S.I. Chan, G.K. Helmkamp and P.O.P. Ts'o, J. Am. Chem. Soc., 86, 696 (1964).

16) M.L. Eidenoff and J.E. Knoll, J. Am. Chem. Soc., 75, 1992 (1953).

17) J.W. Jones and R.K. Robins, J. Am. Chem. Soc., 85, 193 (1963).

18) J. Zemlicka and F. Sŏrm, Coll. Czech. Chem. Commun., 30, 1880 (1965).

19) J.J. Fox, I. Wempen, A. Hampton and I.L. Doerr, J. Am. Chem. Soc., 80, 1669 (1958). 
6-methylthioinosine, ${ }^{19)}$ 6-chloropurine riboside, ${ }^{20)}$ adenosine 1-oxide, ${ }^{21)}$ 2',3'-isopropylidene adenosine, ${ }^{22)}$ 9-methyladenine. ${ }^{23)}$

pD Measurements__ values which are the values obtained with a standard $\mathrm{pH}$-meter measuring $\mathrm{D}_{2} \mathrm{O}$ solutions.

Rate Measurements - The exchange rates were measured with $30 \mathrm{mg}$ of the purine derivative dissolved in $0.5 \mathrm{ml}$ of $\mathrm{D}_{2} \mathrm{O}$ containing $0.2 \mathrm{M}$ phosphate buffer and $30 \% \mathrm{w} / \mathrm{v}$ hexadeuteriodimethylsulfoxide $\left.\left(\mathrm{DMSO}-d_{6}\right),{ }^{24}\right)$ adjusted to an appropriate $\mathrm{pD}$ value for the reaction. Readjustments of $\mathrm{pD}$ values were made for each test solution by addition of dibasic or monobasic phosphate solution before the reaction started. Aqueous $10 \% \mathrm{NaOD}$ was added to obtain strongly alkaline solutions. The reactions were carried out in a
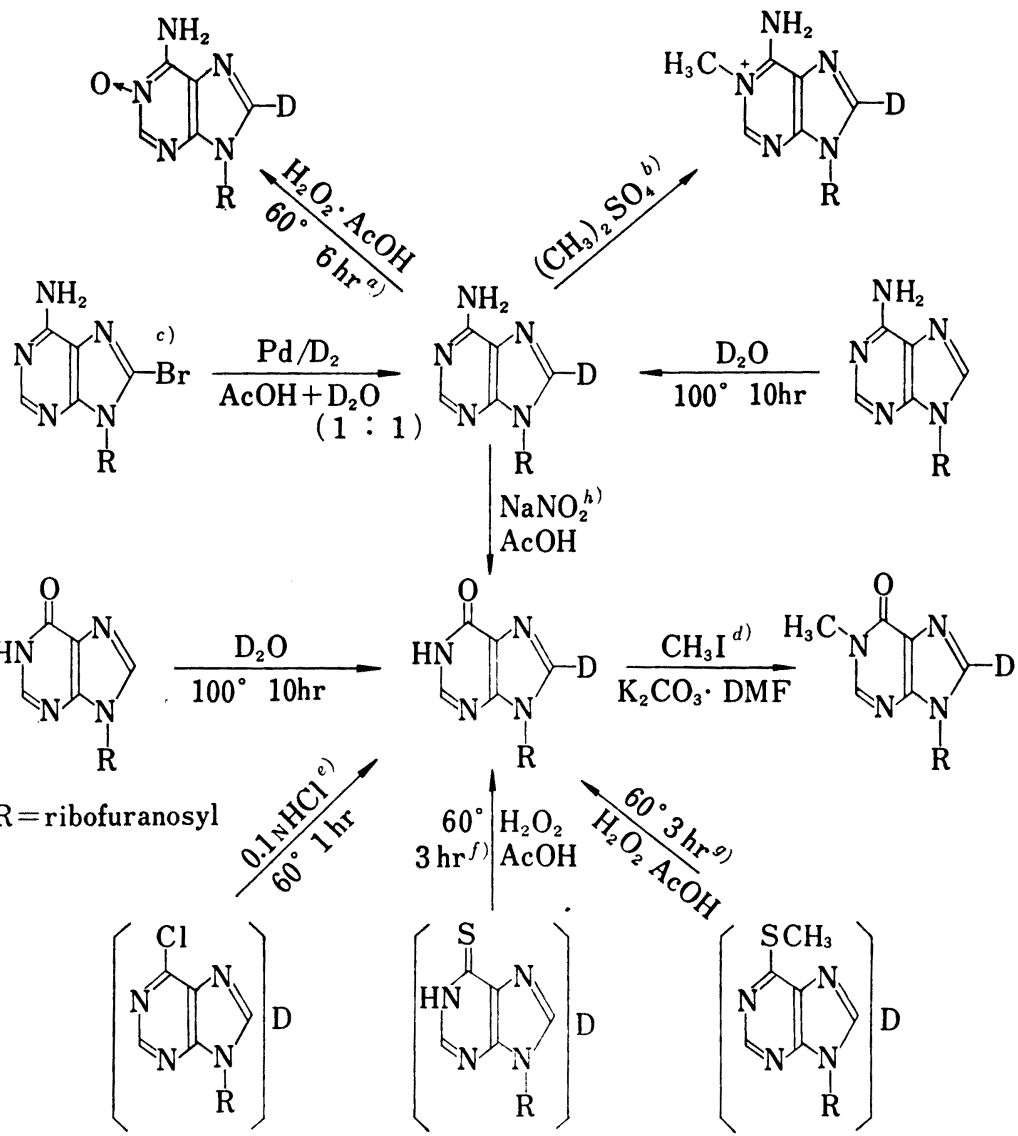

Chart 1

a) M.A. Stevens and G.B. Brown, J. Am. Chem. Soc., 80, 2759 (1958); M.A. Stevens, D.I. Magrath, H.W. Smith and G.B. Brown, ibid., 80, 2755 (1958)

b) A.D. Broom, L.B. Townsent, J.W. Jones and R.K. Robins, Biochemistry, 8, 494 (1964)

c) M. Ikehara, M. Kaneko and S. Uesugi, Chem. Commun., 1987, 17

d) J.W. Jones and R.K. Robins, J. Am. Chem. Soc., 85, 193 (1963)

e) H.J. Schaffer and E. Odin, J. Med. Chem., 10, 181 (1967)

f) J.F. Gerster and R.K. Robins, J. Org. Chem., 31, 3258 (1966)

g) J.G. Gerster and R.K. Robins, J. Am. Chem. Soc., 87, 3752 (1965)

h) K. Lohmann, Biochem. Z., 254, 381 (1932)

20) J.F. Gerster, J.W. Jones and R.K. Robins, J. Org. Chem., 28, 945 (1963).

21) M.A. Stevens, D.I. Magrath, H.W. Smith and G.B. Brown, J. Am. Chem. Soc., 80, 2755 (1958).

22) A. Hampton, J. Am. Chem. Soc., 83, 3643 (1961).

23) J.C. Myers and L. Zeleznik, J. Org. Chem., 28, 2087 (1963).

24) DMSO was added to obtain homogeneous solutions of the nucleosides at appropriate concentrations for the NMR measurements at room temperature. 
sealed nuclear magnetic resonance (NMR) sample tube at an appropriate reaction temperature and the reaction were followed by NMR spectra. The rates for the exchange are expressed as pseudo-first order. reaction rates.

\section{Result}

\section{Structures of Deuterated Products}

The hydrogens exchanged were proved to be the C-8 and not the C-2 hydrogens in all the 6 -substituted derivatives studied on the basis of chemical evidence, as illustrated in Chart 1.

The deuterated product from adenosine was identical with 8-deuterioadenosine which was derived by catalytic debromination of 8 -bromoadenosine with $\mathrm{D}_{2}$ gas. 8-Deuterioadenosine which was derived by catalytic debromination of 8-bromoadenosine with $\mathrm{D}_{2}$ gas. 8Deuterioadenosine, whose structural identity was thus established, was converted by treatment with sodium nitrite into 8-deuterioinosine which was identical with that obtained by direct deuteration of inosine. Acid-hydrolyses of deuterated 6-thio-, 6-methylthio-, and 6-chloro-derivatives gave deuterioinosine which in each case was identical with 8-deuterioinosine. Deuterio- $\mathrm{N}_{6}$-methyladenosine was identical with the corresponding 8-deuterio derivative which was obtained by thermal rearrangement of 8-deuterio-1-methyladenosine derived by methylation of 8-deuterioadenosine. 8-Deuterioinosine was methylated into 8deuterio-1-methylinosine which was identical with the deuteration product of 1-methylinosine. Structural identification of 8-deuterio- $\mathrm{N}_{6}, \mathrm{~N}_{6}$-dimethyladenosine and 2-aminopurine riboside was based on comparison of their NMR spectra with those of all the compounds chemically identified in the present study.

\section{Rates of Exchange with 6-Substituted Purine Ribosides in Neutral Medium}

Fourteen substituted purine ribosides were deuterated at $81^{\circ}$ in a phosphate buffer at $\mathrm{pD} 7.0$, the reaction rates being shown in Table I. Thermodynamic parameters were given of some of the derivatives under the same condition, as shown in Table II.

TABle I. Pseudo-First Order Rate Constants and Half-Lives for Exchange of C-8 Hydrogen of Purine Ribosides in $\left.\mathrm{pD} 7.0^{a}\right) \mathrm{D}_{2} \mathrm{O}-\mathrm{DMSO}$ at $81^{\circ}$

\begin{tabular}{lcc}
\hline \multicolumn{1}{c}{ Derivative } & $\begin{array}{c}\text { Pseudo-first order } \\
\text { rate constant } \\
\left(10^{-5} \mathrm{sec}^{-1}\right)\end{array}$ & $\begin{array}{c}\text { Half-life } \\
\text { (hours) }\end{array}$ \\
\hline Adenine & 2.40 & 8.02 \\
9-Methyladenine & 5.40 & 3.57 \\
Adenosine & 6.06 & 3.18 \\
$2^{\prime}$-Deoxyadenosine & 5.40 & 3.57 \\
$2^{\prime}, 3^{\prime}$-Isopropylideneadenosine & 6.50 & 2.97 \\
Adenosine 1-oxide & 0.00 & $\infty$ \\
$\mathrm{N}_{6}$-Methyladenosine & 5.26 & 3.67 \\
$\mathrm{~N}_{6}, \mathrm{~N}_{6}$-Dimethyladenosine & 2.63 & 7.32 \\
Inosine & 9.46 & 2.00 \\
1-Methylinosine & 6.90 & 2.78 \\
6-Thioinosine & 25.4 & 0.70 \\
6-Methylthioinosine & 3.21 & 6.00 \\
6-Chloropurine riboside & 1.31 & 14.70 \\
2-Aminopurine riboside & 13.19 & 1.47 \\
\hline
\end{tabular}

a) The solvent consisted of $0.2 \mathrm{M}$ phosphate buffer of $\mathrm{D}_{\mathrm{z}} \mathrm{O}$ and $\mathrm{C} .30 \% \mathrm{w} / \mathrm{v}$ DMSO- $d_{6}$. The pD value is $\mathrm{pH}^{\prime}$ which was the value obtained with a standard $\mathrm{pH}$-meter measuring $\mathrm{D}_{\mathrm{g}} \mathrm{O}$ solution.

b) This derivative exsists as its anionic form at $\mathrm{pD}$ 7.0. The rate constant of non-dissociated species was $7.5 \times 10^{-5} \mathrm{sec}^{-1}$ which was obtained in pD 5.0 solufon. 
TABle II. Activation Parameters for Exchange of C-8 Hydrogen of Purine Ribosides ${ }^{a}$ )

\begin{tabular}{lccc}
\hline \hline Derivative & $\begin{array}{c}\text { 2nd order } \\
\text { rate constant } \\
\left(10^{-6} \times \mathrm{L} \mathrm{mole} \mathrm{mec}^{-1}\right)\end{array}$ & $\begin{array}{c}\text { Energy of } \\
\text { activation } \\
(\mathrm{kcal} / \mathrm{mole})\end{array}$ & $\begin{array}{c}\text { Entropy of } \\
\text { activation } \\
(e . u .)\end{array}$ \\
\hline Adenosine & 1.68 & 17.2 & -38.6 \\
$\mathrm{~N}_{6}$-Methyladenosine & 1.92 & 20.91 & -32.3 \\
$\mathrm{~N}_{6}, \mathrm{~N}_{6}$-Dimethyladenosine & 1.46 & 17.4 & -37.5 \\
Inosine & 2.63 & 23.0 & -23.2 \\
6-Thioinosine & & 16.4 & -37.6 \\
\hline
\end{tabular}

a) The reaction solvent consisted of $0.2 \mathrm{M}$ phosphate buffer $\mathrm{pD} 7.0$ of $\mathrm{D}_{3} \mathrm{O}$ and $30 \% \mathrm{w} / \mathrm{v}$ DMSO- $d_{\mathrm{g}}$. pD 7.0 was obtained with a standard $\mathrm{pH}$-meter measuring the tested solution.

b) rate constant at $81^{\circ}$

c) 6-Thioinosine exists as its anionic form at this $\mathrm{pD}$.

\section{Correlation of the Rates with Hammett Parameters}

Figure 1 represents plots of $\log \mathrm{k}_{2}$ versus the Brown-Okamoto ${\sigma_{\mathrm{p}}}^{+}$values. ${ }^{25)}$ It may be revealed from the figure that an electron-withdrawing substituent at the C- 6 position tends to reduce the rate for the hydrogen exchange at the $\mathrm{C}-8$ position, whereas an electron-donating group at the C-6 position facilitates the exchange. ${ }^{26}$ ) The electrophilic character of this exchange reaction can also be supported by correlating the rates with the NMR chemical shifts of C-8 hydrogens, ${ }^{27-29)}$ as illustrated in Fig. ${ }^{\left.2{ }^{26}\right)}$ The chemical shift may, in general, be regarded as a measure of the electron density on the carbon atom carrying the hydrogen concerned. Thus, a hydrogen which resonated at a higher magnetic field exchanged more readily than the one which resonated at a lower field. It can, therefore, be suggested that the rate-determining step in the hydrogen exchange of these derivatives may involve an electrophilic attack by the reagent, which is supposed to be $\mathrm{D}^{+}$(or $\mathrm{D}_{3} \mathrm{O}^{+}$) ion or $\mathrm{D}_{2} \mathrm{O}$ molecule.

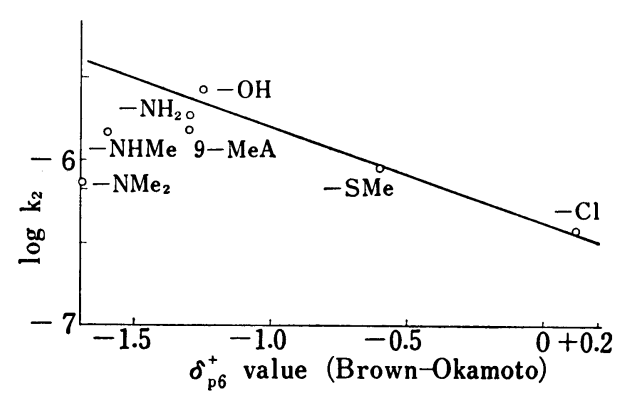

Fig. 1. Correlation between Second-order Rate Constants and Brown-Okamoto $\sigma_{\mathrm{p}}{ }^{+}$ Values

$k_{3}$ is a rate constant when the rate is assumed to be expressed as $k_{1}\left[D_{2} O\right][P u]$.

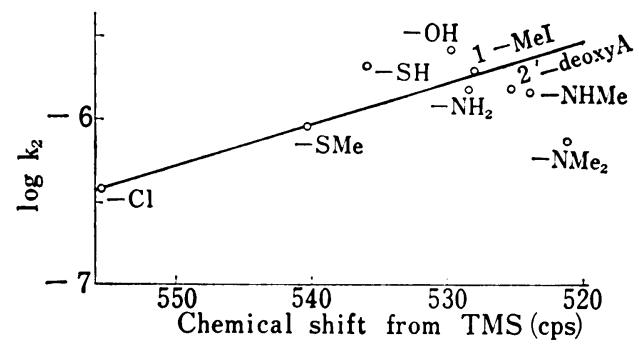

Fig. 2. Correlation between Second-order Rate Constants and Chemical Shifts of 8Hydrogens.

$k_{2}$ is a rate constant when the rate is assumed to be expressed as $\mathrm{k}_{\mathbf{2}}\left[\mathrm{D}_{\mathbf{2}} \mathrm{O}\right][\mathrm{Pu}]$.

25) H.C. Brown and Y. Okamoto, J. Am. Chem. Soc., 80, 4979 (1958).

26) An appreciable deviation from the linearity was found with $\mathrm{N}_{6}$-methyl and, especially $\mathrm{N}_{6}, \mathrm{~N}_{6}$-dimethyl derivatives. It may be explained by a reduced resonance effect of these groups due to electric repulsive effect of $\mathrm{N}_{7}$-nitrogen compared with those substituted in para position of benzene ring.

27) A.D. Broom, M.P. Schweizer and P.O.P.Ts'o, J. Am. Chem. Soc., 89, 3612 (1967).

28) W.C. Coburn, Jr., M.C. Thorpe, J.A. Montgomery and K. Hewson, J. Org. Chem., 30, 1110 (1965).

29) Idem, J. Org. Chem., 30, 1114 (1965). 


\section{Rate-pD Profile in Hydrogen Exchange}

Adenosine was treated in various $\mathrm{pD}$ media at $81^{\circ}$. The rate- $\mathrm{pD}$ profile, as shown in Fig. 3, indicates that the rate was independent of the deuterium ion concentration over a considerably wide range of $\mathrm{pD}$ and that the reaction was abruptly accelerated at a $\mathrm{pD}$ medium between 12 and 13. Another feature of the reaction is that the rate was reduced by decreasing $\mathrm{pD}$ of the medium to below $\mathrm{pD} 4$. All of these features of the pD-profile hold with 9-methyladenine and 2'-deoxyadenosine. Contrary to these 9-substituted adenine derivatives, the exchange rate of adenine itself containing a free $\mathrm{N}_{9}-\mathrm{H}$ group in the molecule was markedly decreased at a $\mathrm{pD}$ of 9.5 and completely fallen to zero in a more alkaline medium than this $\mathrm{pD}$ value under the reaction condition chosen in the present study.

The characteristic pD-profile of adenine derivatives described above may enable us to correlate the exchange rate with structural changes of the substrate molecule. Namely, $\mathrm{pD}$ at one of inflection points of the rate-curve coincides with $\mathrm{p} K_{\mathrm{a}_{1}}$ value, 4.7 , of adenine derivatives (due to deprotonation of $\mathrm{N}_{1}$-protonated conjugate acid) and $\mathrm{pD}$ at another inflection point coincides with $\mathrm{pK}_{\mathrm{a}_{2}}$ of 9.8 of adenine (due to dissociation of $\mathrm{N}_{9}-\mathrm{H}$ hydrogen). The fact that 1-methyladenosine, whose $\mathrm{p}_{\mathrm{a}}$ is 7.8 , did not undergo the exchange in a neutral medium can be explained by taking account that it exists as a cation at $\mathrm{pD}$ 7.0. Although the $\mathrm{pD}$ value at the third inflection point, about 12.0 , shown by 9 -substituted adenine derivatives is almost equal to the $\mathrm{p} K_{\mathrm{a}}$ value due to dissociation of $2^{\prime}-\mathrm{OH}$ hydrogen in the ribose moiety of adenosine there is no basis for correlating the change in rate with structural changes in the molecule, because an inflection point at the same $\mathrm{pD}$ value appeared in the rate-profiles of 9 -methyladenine, $2^{\prime}$-deoxyadenosine, and $2^{\prime}, 3^{\prime}$-isopropylidene adenosine. Therefore, the increase in the rate of 9 -substituted derivatives in this $\mathrm{pD}$ region should be attributed to factors other than the structural change in the substrate molecule. This will be discussed in the last part of Discussion of this paper.

Inosine and thioinosine, which have an acidic hydrogen in the molecule, showed another characteristic feature in their rate-profiles. The profile of inosine, as shown in Fig. 4, indicates an inflection point at $\mathrm{pD} 8.5$, which corresponds well to the $\mathrm{p} K_{\mathrm{a}}$ value of 8.8 due to hydrogen dissociation from $\mathrm{N}_{1}-\mathrm{H}$ group of inosine. No further acceleration in the exchange rate was obtained even in a medium as alkaline as $\mathrm{pD} 12$. This is also the case with thioinosine, where the rate-profile showed an inflection point at $\mathrm{pD}$ 7.0. This $\mathrm{pD}$ value coincides with

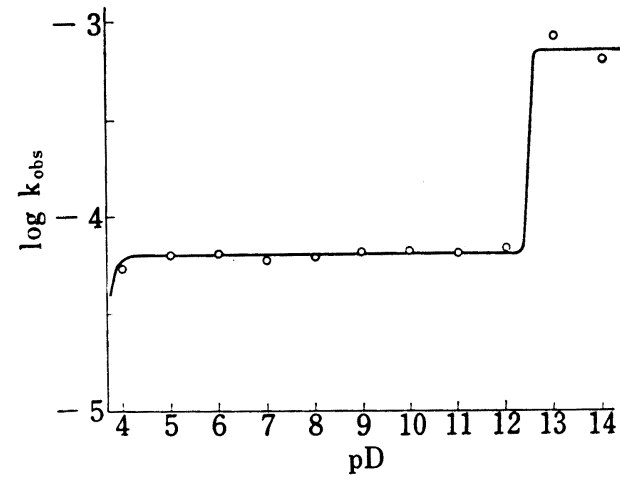

Fig. 3. $\log \mathrm{k}_{\mathrm{obs}}-\mathrm{pD}$ Profile for Hydrogen Exchange in Adenosine

$k_{\circ b}$ is an observed pseudo-first order rate constant when the reaction is assumed to be a first order only in purines.

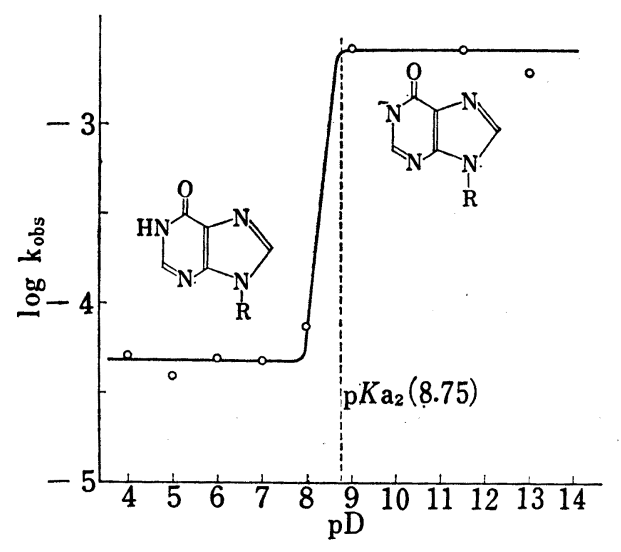

Fig. 4. $\log \mathrm{k}_{\mathrm{obs}}-\mathrm{pD}$ Profile for Hydrogen Exchange in Inosine

$\mathbf{k}_{\mathrm{obs}}$ is an observed pseudo-first order rate constant when the reaction is assumed to be a first order only in purines. 
the $\mathrm{p} K_{\mathrm{a}}$ value of thioinosine. The $\mathrm{pD}$-dependent change in the rate of inosine can tentatively be correlated with structural changes of inosine as illustrated in Fig. 4.

\section{Dependence of the Rate on Concentration of $\mathrm{D}_{\mathbf{2}} \mathrm{O}$}

The fact that the rate was independent of $\mathrm{pD}$ of the medium over a considerably wide $\mathrm{pD}$ range suggests that the rate may depend on a molar concentration of water but not of $\mathrm{D}^{+}$ or $\mathrm{OD}^{-}$ion. Fig. 5 shows the rate-dependence on molar concentration of $\mathrm{D}_{2} \mathrm{O}$ in DMSO indicating that the pseudo first order rate, $k_{1}$, may be written as $k_{2}\left[D_{2} O\right]$. Fig. 6 shows the rate-profile over a range of concentrations of $\mathrm{D}_{2} \mathrm{O}$ in DMSO.

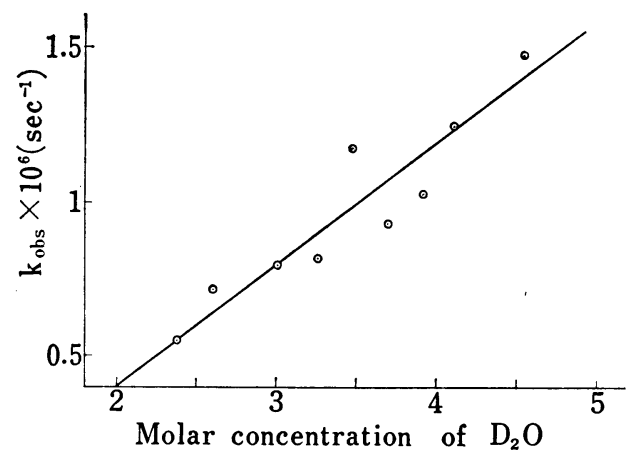

Fig. 5. Dependence of $\mathbf{k}_{\text {obs }}$ for Hydogen Exchange in Adenosine on $\mathrm{D}_{2} \mathrm{O}$ Molar Concentration in Dimethylsulfoxide at $80^{\circ}$

$\mathbf{k}_{\text {obs }}$ is an observed pseudo-first order rate constant when the reaction is assumed to be a first order only in purines.



Fig. 6. Dependence of $\mathbf{k}_{\text {obs }}$ for Hydrogen Exchange in Adenosine on $\mathrm{D}_{2} \mathrm{O}$ Molar Concentration in Dimethylsulfoxide at $80^{\circ}$

$k_{o b s}$ is an observed pseudo-first order rate constant when the reaction is assumed to be a first order only in purines.

\section{Dependence of the Rate on Factors Other than $\mathrm{pD}$ and $\left[\mathrm{D}_{\mathbf{2}} \mathbf{0}\right]$}

When the substrate was deprotonated to the corresponding conjugate base, the rate

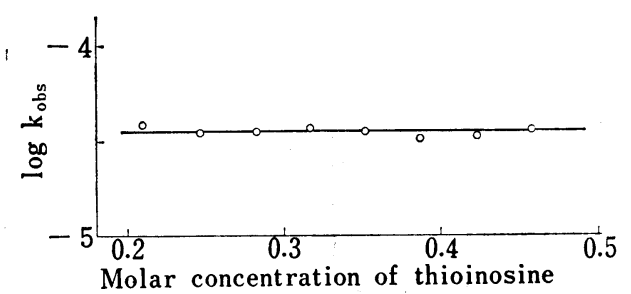

Fig. 7. Dependence of $\mathbf{k}_{\text {ods }}$ for Hydrogen Exchange in Adenosine on Molar Concentration of Thioinosine in $0.2 \mathrm{M}$ Phosphate Buffer et pD 9.0 at $40^{\circ}$

$\mathbf{k}_{\text {obs }}$ is an observed pseudo-first order rate constant when the reaction is assumed to be a first order only in purines. was abruptly increased as demonstrated with inosine and thioinosine. It would, therefore, be possible to suppose that the anionic conjugate base might play the part of the reagent to abstract the hydrogen at the $\mathrm{C}-8$ position, thus yielding a marked increase in the rate at a $\mathrm{pD}$ around the $\mathrm{p} K_{\mathrm{a}}$. But this is not the case. since it was shown that the rate of hydrogen exchange of adenosine was not affected at all in the presence of $0.2-0.5 \mathrm{~m}$ thioinosine in pD 9.0 solutions, as represented in Fig. 7.30) In addition to this, imidazole, a representative nucleophilic catalyst, did not affect the rate of adenosine in $\mathrm{pD} 9.0$ solution.

\section{Discussion}

The reaction profile of the hydrogen exchange investigated in the present study may be summarized as follows.

30) Thioinosine is almost completely ionized at this $\mathrm{pD}$. 
1) Protonated species of purine derivatives, i.e., when measured in more acidic media than their $\mathrm{p} K_{\mathrm{a}_{1}}$, strongly resisted exchange of the $\mathrm{C}-8$ hydrogens.

2) When hydrogen-dissociatoin of the derivatives gave the corresponding conjugate bases, the exchange rate was facilitated to a marked extent; for example, in cases where inosine and thioinosine were treated in more alkaline $\mathrm{pD}$ media than their $\mathrm{p} K_{\mathrm{a}_{2}}$ values.

3) Dissociation of $\mathrm{N}_{9}-\mathrm{H}$ to the anion eliminated completely the rate of exchange of C-8 hydrogen.

4) Within a $\mathrm{pD}$ range where the structure of the substrate was unchanged (i.e., neither protonated nor deprotonated), the rate was independent of $\mathrm{pD}$ in the medium and was approximately first order in $\left[\mathrm{D}_{2} \mathrm{O}\right]$.

5) The rate of exchange with $\mathrm{N}_{9}$-substituted purines increased abruptly in media more alkaline than $\mathrm{pD} 12$. This unexplainable increase in the rate was not observed in the $\mathrm{pD}$ rate profiles of inosine nor thioinosine as anions in a strongly alkaline media.

6) When an electron-withdrawing substituent is introduced onto the C-6 position the rate was reduced, whereas an electron-donating substituent at C- 6 increased the rate. This indicates that the reaction may be characterized as an electrophilic. This is supported by a consideration of the electron density at the $\mathrm{C}-8$ position estimated from the chemical shift data of $\mathrm{C}-8$ proton in NMR spectroscopy.

7) Hydrogens on imidazole and 1-methylimidazole are much more reactive toward exchange than those in the imidazole moieties of purine derivatives. Taking into account that the imidazole moiety of purines is rather electron-deficient compared with imidazole itself, it may be concluded that the exchange reactivity is reduced by a decrease in the electron density of the imidazole ring concerned.

In addition to the features described above, we know that $\mathrm{C}-8$ hydrogens of $\mathrm{N}_{7}$-quaternized purine derivatives, for example, 7-methylguanosine, 7-methylinosine, etc., undergo very facile hydrogen-exchange even at room temperature. ${ }^{3,10}$

The reaction mechanism proposed for this exchange should account for all the kinetic data as well as other available chemical evidences that we have at present. The following mechanism $\mathrm{A}$ and $\mathrm{B}$ can be proposed for this type of hydrogen exchange and they fit all the rateprofiles described in the present study.

Mechanism A, where $\mathrm{N}_{7}$-protonated species of the substrate is attacked by $\mathrm{OD}^{-}$.

$$
\begin{aligned}
& \text { Rate }=k_{0 D^{-}}\left[\mathrm{OD}^{-}\right]\left[\mathrm{PuN}_{7}{ }^{+}\right] \\
& {[\mathrm{Pu}]=\left[\mathrm{PuN}_{7}+\right]+\left[\mathrm{PuN}_{7}{ }^{\circ}\right]} \\
& \mathrm{Ka}\left(\mathrm{N}_{7}\right)=\left[\mathrm{PuN}_{7}^{\circ}\right]\left[\mathrm{D}^{+}\right] /\left[\mathrm{PuN}_{7}{ }^{+}\right]
\end{aligned}
$$

where $[\mathrm{Pu}]$ is a concentration of the purine derivative used in total and $\mathrm{Ka}\left(\mathrm{N}_{7}\right)$ is not a $\mathrm{p} K_{\mathbf{a}_{1}}$ of a substrate but an imaginary dissociation constant due to protonation of the $\mathrm{N}_{7}$-nitrogen.

Therefore, the equation is transformed to

$$
\text { Rate }=\left\{k_{\mathrm{OD}}-\left[\mathrm{OD}^{-}\right]\left[\mathrm{D}^{+}\right] /\left(\mathrm{Ka}\left(\mathrm{N}_{7}\right)+\left[\mathrm{D}^{+}\right]\right)\right\}[\mathrm{Pu}]
$$

Actually, $\left[\mathrm{PuN}_{7}{ }^{+}\right]$is negligibly small in all the $\mathrm{pD}$ region examined, i.e., always $\mathrm{Ka}\left(\mathrm{N}_{7}\right) \gg\left[\mathrm{D}^{+}\right]$. Therefore,

$$
\text { Rate }=\left\{k_{\mathrm{OD}^{-}} K_{\mathrm{D}_{\mathbf{2}} \mathrm{O}} / \mathrm{Ka}\left(\mathrm{N}_{7}\right)\right\}\left[\mathrm{D}_{2} \mathrm{O}\right][\mathrm{Pu}]
$$

Namely, the observed second order rate constant, $\mathrm{k}_{2}$, can be expressed as

$$
\log k_{2}=\log k_{\mathrm{OD}^{-}}+\log K_{\mathrm{D}_{\mathbf{2}} \mathrm{O}}+\mathrm{p} K_{\mathrm{a}}\left(\mathrm{N}_{7}\right)
$$

where $\mathrm{K}_{\mathrm{OD}^{-}}$is a rate constant for the hydrogen exchange of a $\mathrm{N}_{7}$-protonated conjugate acid by $\mathrm{OD}^{-}$and $\mathrm{K}_{\mathrm{D}_{2} \mathrm{O}}$ is dissociation constant of $\mathrm{D}_{2} \mathrm{O}$.

It turns out that the rate is proportional to a molar concentration of $\mathrm{D}_{2} \mathrm{O}$ in the reaction medium and can be expressed as a pseudo-first order reaction with respect to purines when the $\mathrm{D}$-content of the medium is large enough. The rate equation also indicates that the ob- 
served rate constants is proportional to the basicity of $\mathrm{N}_{\mathbf{7}}$-nitrogen but this cannot be verified since the first protonation may actually occur at a nitrogen in the pyrimidine moieties of purine molecules. When the substrate is dissociated to a conjugate base (for example, inosine to anionic inosinate), the basicity of $\mathrm{N}_{7}$-nitrogen must be increased. Therefore, the rates for inosine and thioinosine are expected to rise abruptly at the $\mathrm{pD}$ range around their $\mathrm{p} K_{\mathrm{a}_{2}}$ values. The electron-donating substituent at C-6 position increases the basicity of $\mathrm{N}_{7}$-nitrogen, hence $\mathrm{k}_{\mathrm{obs}}$ becomes larger. When the substrate is protonated in acidic media, on the other hand, the basicity of $\mathrm{N}_{7}$-nitrogen decreases to a marked extent, hence $\mathrm{k}_{\mathrm{ob}}$ becomes much smaller. When the $\mathrm{N}_{9}-\mathrm{H}$ of purine bases, adenine, hypoxanthine, etc., is dissociated into the conjugate base, the ylide structure produced is greatly destabilized, so that it strongly resists the exchange. The mechanism A may be presented as shown in Chart 2 .

mechanism A<smiles>[X]c1ncnc2c1nc([PH3+])n2[R]</smiles><smiles>[X]c1ncnc2c1[n+]([O-])cn2[R]</smiles>

mechanism B<smiles>[X]c1ncnc2c1nc([PH2+])n2[Y]([2H])O[2H]</smiles>
or<smiles>[X]c1ncnc2c1nc([R])n2[R]</smiles>

Chart 2

Mechanism B, where non-cationic $N_{7}$ species of substrate is attacked by $D_{2} O$ in such a way as to fit the electrophilic characteristcs of the reaction described in this study.

$$
\text { Rate }=k_{\mathrm{D}_{2} \mathrm{O}}\left[\mathrm{D}_{2} \mathrm{O}\right][\mathrm{Pu}]^{31)}
$$

For example, such processes as shown in Chart 2 may be realized.

Both mechanisms A and B fit all of the rate-profiles obtained so far and one cannot determine which mechanism is actually operating in this type of hydrogen exchange. The essential difference between mechanism $\mathrm{A}$ and $\mathrm{B}$ is that the former involves a two step reaction with $\mathrm{D}^{+}$and $\mathrm{OD}^{-}$, respectively, whereas the latter involves a concerted protonation-deprotonation process with a $\mathrm{D}_{2} \mathrm{O}$ molecule. Further study required for complete elucidation of the reaction mechanism is now being pursued in our laboratory.

It is to be noted that mechanism $A$ is the same as that proposed for hydrogen exchange of the C-2 hydrogens in imidazole and 1-methylimidazole by Vaughan, et al., ${ }^{32)}$ and that mechanism $\mathrm{B}$ is similar to that proposed for pyrimidones by Beak, et al. ${ }^{33}$ )

One feature of the rate-profiles still remains unexplained by either the Mechanism A or B. Namely, the rates of exchange with neutral species of the substrates increase abruptly

31) In all the $\mathrm{pD}$ region, $\mathrm{N}_{7}$-nitrogen is considered to be non-cationic, hence $\left[\mathrm{PuN}^{\circ}\right]=[\mathrm{Pu}]$.

32) J.D. Vaughan, Z. Mughrabi and E.C. Wu, J. Org. Chem., 35, 1141 (1970).

33) P. Beak and E.M. Monroe, J. Org. Chem., 34, 589 (1969). 
at around $\mathrm{pD}$ 12. The exchange in this medium is supposed to go by a different mechanism, that is, the $\mathrm{C}-8$ hydrogen is abstracted by $\mathrm{OD}^{-}$just as in those cases where the ring hydrogens in benzene, pyridine, etc., are exchanged in strongly alkaline media at an elevated temperature. The fact that dissociated inosinate did not show this abrupt increase may be explained by the effect of the anionic substituent in decreasing the acidity of $\mathrm{C}-8$ hydrogen. Vaughan, et al. described that this kind of mechanism was also operating in the exchange of imidazole derivatives in strongly alkaline media. ${ }^{32)}$

Finally, it should be mentioned that a $\mathrm{D}_{2} \mathrm{O}$ molecule may possibly take place of $\mathrm{OD}^{-}$ especially in a strongly acidic medium. Thus, the rate equation may be written as a general form,

$$
\text { Rate }=\left\{k_{\mathrm{OD}}-\left[\mathrm{OD}^{-}\right]+k_{\mathrm{D}_{0} 0}\left[\mathrm{D}_{2} \mathrm{O}\right]\right\}\left[\mathrm{PuN}_{7}{ }^{+}\right]
$$

Supposing that the substrate would be completely protonated at the $\mathrm{N}_{\mathbf{7}}$-nitrogen, the equation may be simplified as

$$
\text { Rate }=\left\{k_{O D^{-}}\left[\mathrm{OD}^{-}\right]+k_{\mathrm{D}_{2}}\right\}\left[\mathrm{D}_{2} \mathrm{O}\right][\mathrm{Pu}]
$$

Then, where $\mathrm{k}_{\mathrm{OD}^{-}}\left[\mathrm{OD}^{-}\right] \ll \mathrm{k}_{\mathrm{D}_{2} \mathrm{O}}$,

$$
\text { Rate }=k_{\mathrm{D}_{2} \mathrm{O}}\left[\mathrm{D}_{2} \mathrm{O}\right][\mathrm{Pu}]
$$

As reported by Vaughan, et al., ${ }^{32)}$ hydrogen exchange of imidazole fits the rate equation described above in acidic media.

Acknowledgement The authors are greately indebted to Dr. Waro Nakahara, Director of National Cancer Center Research Institute (Tokyo), for his hearty encouragement and Professor G.M. Tener of The University of British Columbia for critical reading of this paper before publication. 